\title{
Musical chairs mortality functions: density-dependent deaths caused by competition for unguarded refuges
}

\author{
Jameal F. Samhouri $\cdot$ Richard R. Vance . \\ Graham E. Forrester · Mark A. Steele
}

Received: 28 July 2008 / Accepted: 9 February 2009/Published online: 5 March 2009

(C) The Author(s) 2009. This article is published with open access at Springerlink.com

\begin{abstract}
Structural refuges within which prey can escape from predators can be an important limiting resource for the prey. In a manner that resembles the childhood game of musical chairs, many prey species rapidly retreat to shared, unguarded refuges whenever a predator threatens, and only when refuges are relatively abundant do all prey individuals actually escape. The key feature of this process is that the per capita prey mortality rate depends on the ratio of prey individuals to refuges. We introduce a new class of mortality functions with this feature and then demonstrate statistically that they describe field mortality data from a well-studied coral reef fish species, the Caribbean bridled goby Coryphopterus glaucofraenum, substantially better than do several mortality functions of more conventional form.
\end{abstract}

Communicated by Jeff Shima.

J. F. Samhouri and R. R. Vance contributed equally to this work.

J. F. Samhouri · R. R. Vance

Department of Ecology and Evolutionary Biology,

University of California, Los Angeles, CA 90095-1606, USA

G. E. Forrester

Department of Natural Resources Science,

University of Rhode Island, Kingston, RI 02881, USA

M. A. Steele

Department of Biology, California State University

at Northridge, 18111 Nordhoff Street, Northridge,

CA 91330-8303, USA

J. F. Samhouri $(\bowtie)$

NOAA Fisheries, Northwest Fisheries Science Center,

2725 Montlake Blvd. E, Seattle, WA 98112, USA

e-mail: Jameal.Samhouri@noaa.gov
Keywords Refuges - Mortality functions . Coral reef fish · Density dependence .

Coryphopterus glaucofraenum

\section{Introduction}

Refuges reduce vulnerability of prey to predators (Jeffries and Lawton 1984). A refuge can be structural (e.g., burrows, heavy vegetation, crevices) or temporal (e.g., via migration or diel activity patterns), or it can arise from individual traits (e.g., body size) or behaviors (e.g., group living) (Sih 1987). Structural features of the habitat that provide shelter are perhaps the most common type of refuge in nature (Berryman and Hawkins 2006). Examples abound of terrestrial, aquatic, and marine prey species that use structural refuges to reduce predation risk, including sparrows (Pulliam and Mills 1977; Lima 1990), rodents (Koivunen et al. 2003), insects (Ame et al. 2006; Riihimaki et al. 2006), amphibians (Sih et al. 1988; Babbitt and Tanner 1998), crabs (Fernandez et al. 1993; Hovel and Lipcius 2001), lobsters (Wahle and Steneck 1991; Eggleston and Lipcius 1992), and marine fishes (Ebeling and Laur 1985; Shulman 1985; Rangeley and Kramer 1998; Anderson 2001; Holbrook and Schmitt 2002; Forrester and Steele 2004; Hixon and Jones 2005; Johnson 2006; Caddy 2008).

The importance of structural refuges in mediating predator-prey interactions is widely appreciated in both the theoretical and empirical literature (reviewed by Berryman and Hawkins 2006). Commonly, theoretical models that incorporate prey refuge use focus on predator-prey dynamics (e.g., Cosner et al. 1999; Gonzales-Olivares and Ramos-Jiliberto 2003). This focus applies only if predators are specialists and all aspects of predator as well as prey dynamics are fully understood and specified. Mathematical 
descriptions of structural refuges (e.g., Rosenzweig and MacArthur 1963; Vance 1978) typically assume that a fixed number of prey are able to shelter safely in refuges (but see Sih 1987; Ruxton 1995; Abrams and Walters 1996; Ame et al. 2006). This fixed number formulation assumes that per capita prey mortality depends on the arithmetic difference between prey density and refuge density. It is most appropriate for prey in which every individual uses a single, unshared, and typically guarded refuge at low population densities but some prey must live outside refuges and consequently experience greater vulnerability to predation at higher population density [e.g., some sea urchins (Nelson and Vance 1979) and lobsters (Butler and Herrnkind 1997)].

This paper introduces a new class of mortality functions for what we think may be a large second group of prey species. We focus on prey that occupy open spaces most of the time where they are vulnerable to predators and retreat to shared and typically unguarded structural refuges only when threatened or attacked. In such species, it is not true that a fixed number of prey individuals is invulnerable to predators. Rather, all individuals must scramble to find a safe hiding place when a predator threatens. Because this predator avoidance tactic resembles the childhood game of musical chairs, we call our formulations musical chairs functions. We introduce three members of the musical chairs family of mortality functions, show that the statistical fit of all to data from a field experiment involving a well-studied fish species (the bridled goby Coryphopterus glaucofraenum) improves upon the fit of several conventional mortality functions, and then identify the single function that best describes deaths in this species. This function applies at the small spatial scale on which many experimental studies similar to this one are typically performed. Such local functions provide the starting point for developing mathematical descriptions of population dynamics that apply on much larger spatial scales.

\section{Three musical chairs mortality functions}

The mortality functions described in this section are nonmechanistic, rather than being derived from descriptions of spatial relationships between prey and refuges or behavioral processes (e.g., time budgets, foraging behavior, etc.). Such details will differ from species to species. Nonetheless, the musical chairs mortality functions apply to a class of prey in which individuals have access to multiple structural refuges. We assume that these refuges remain unguarded and largely unoccupied except when a predator actually threatens or attacks. Consequently, the arithmetic difference between prey abundance and refuge abundance will not accurately describe prey vulnerability to predators.
Instead, we propose that a more realistic description of prey vulnerability should involve the ratio of prey individuals to refuge space. Predators will capture more prey when this ratio is high and relatively few refuges are available to prey than when it is low and each prey has easier access to refuges.

Let $x$ and $R$ represent the number of prey individuals and the amount of refuge space per meter squared of habitat, respectively. Because the amount of refuge space required by a single prey individual is likely to be related to its body size (Caddy 2008), prey density $x$ should actually incorporate information about prey body sizes in some explicit way, at least when the model is applied to periods long enough to allow substantial somatic growth or to populations composed of individuals of different sizes. For simplicity in describing the models here, however, we imagine that all prey individuals have the same constant body size so that population abundance is well represented by a simple count. Refuge density $R$ should be measured as the number of prey individuals the available refuge space can accommodate. This number may be proportional to the total number of structural refuges, the total area of refuge space, the total perimeter of all refuges, the combined widths of all refuge entrances, the structural complexity of the habitat, or the total amount of protective cover, as best describes the nature of the refuges and how prey individuals use them. For simplicity, in the remainder of this paper we will refer to $R$ simply as the number of refuges present, each of which can accommodate just one prey individual at any one time.

The defining feature of a musical chairs mortality function is that the prey death rate depends upon the ratio $x / R$. Death rates in populations of most organisms are thought to contain both density-independent and densitydependent elements, and we expect prey that escape from predators in unguarded refuges to be no exception. Indeed, capture of such a prey individual can occur for either of two reasons: the prey never detects the predator in the first place, or it does detect the predator but cannot retreat into a refuge soon enough to avoid capture. Deaths of the first kind do not involve refuges at all. Provided refuges are sufficiently plentiful that each prey has exclusive access to as many refuges as desired, then refuge abundance plays no role in the likelihood of capture following predator detection. These causes combine to produce deaths at some density-independent per capita rate $d_{0}$. When refuges are less plentiful, multiple individuals may attempt to occupy the same refuge simultaneously. Alternatively, some individuals may be located farther from refuges when a predator strikes than they would be if refuges were abundant. No matter the precise cause, some individuals will not secure adequate protection when refuges are in short supply, and deaths will occur at a greater rate. In the absence 
of empirical support for any other particular functional form, we make the simplifying assumption that densitydependent deaths arising from refuge competition will occur at a rate given by some coefficient $d_{1}$ times an appropriate measure of crowding that involves the prey/ refuge ratio $x / R$. Because both density-independent deaths (Hixon and Jones 2005) and density-dependent deaths (e.g., Schmitt and Holbrook 2007; White 2008) are highly likely to be influenced by predator abundance, $d_{0}$ and $d_{1}$ are best viewed as functions of predator abundance. The remainder of our treatment does not require this awareness, however, and so for simplicity we will treat $d_{0}$ and $d_{1}$ as constant parameters that we will hereafter regard as positive.

What remains unclear is just how these density-independent and density-dependent components combine to produce the overall death rate. Below we consider three of many possible functions in which prey per capita mortality rate depends upon the ratio of prey individuals to refuges. The first two functions are contrasting idealizations of reality, and the third potentially more realistic function lies between these extremes. Our literature search has revealed no previous mention of any of these three functions.

The first and perhaps simplest possibility is that densityindependent and density-dependent deaths act independently and hence additively, and that the appropriate measure of crowding is simply the ratio $x / R$ itself. Thus, we define the additive musical chairs instantaneous per capita mortality function as

$f_{1}(x)=d_{0}+d_{1} \frac{x}{R}$.

Figure 1a displays the shape of this function. Note that in this function density dependence in the per capita prey mortality rate occurs across all values of $x / R$. The biological interpretation of this functional form is that refuge competition influences prey deaths at all levels of prey density. This function departs from the widely used Beverton-Holt mortality function $d_{0}+d_{1} x$ (Quinn and Deriso 1999; Osenberg et al. 2002) only by its explicit inclusion of refuges.

A second possibility is that the prey population experiences density-dependent mortality only beyond some threshold ratio $x / R$ of prey to refuge density. In this case, the per capita mortality rate is constant for small values of $x / R$ and directly proportional to the prey to refuge ratio for large values of $x / R$. The piecewise musical chairs instantaneous per capita mortality function is

$f_{0}(x)=\left\{\begin{array}{cc}d_{0} & \text { for } \frac{x}{R} \leq \frac{d_{0}}{d_{1}} \\ d_{1} \frac{x}{R} & \text { for } \frac{x}{R}>\frac{d_{0}}{d_{1}}\end{array}\right\}=\max \left[d_{0}, d_{1} \frac{x}{R}\right]$.

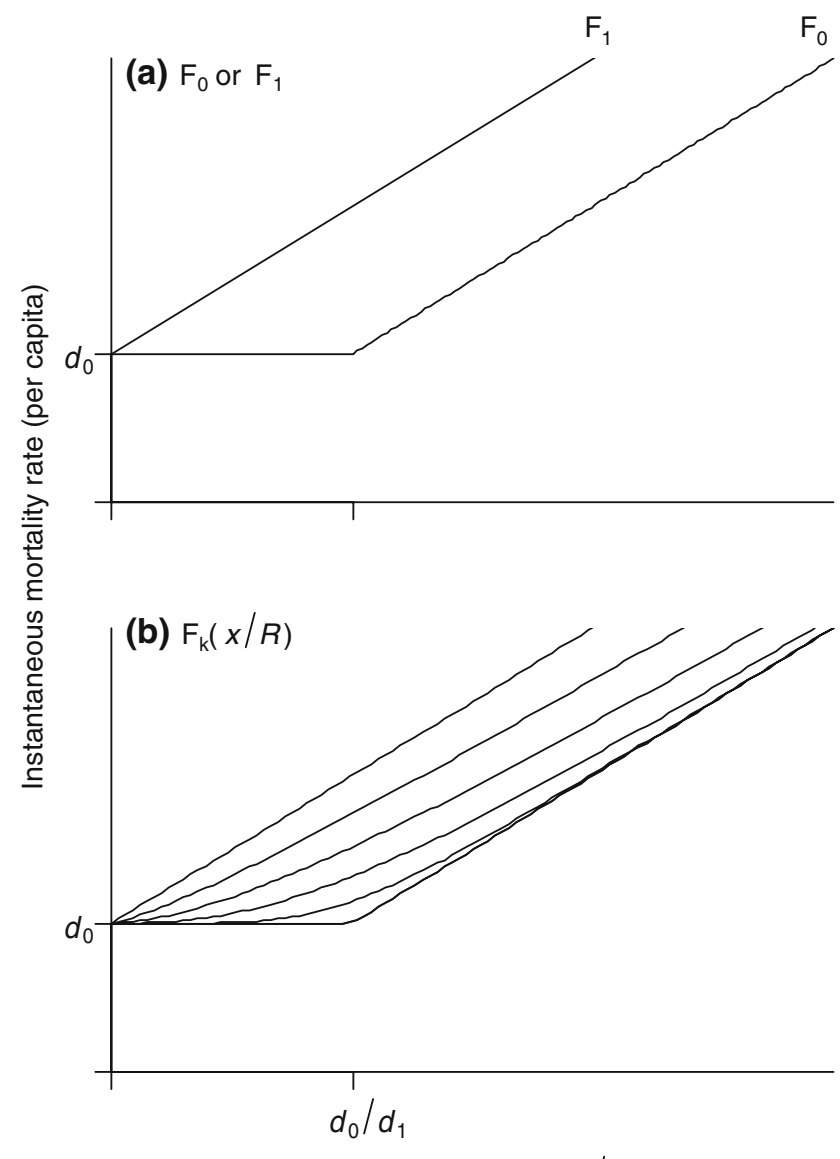

Prey to refuge ratio, $x / R$

Fig. 1 The musical chairs functions are easiest to visualize if the instantaneous per capita mortality rate is plotted against the ratio of prey to refuges $x / R$. Toward this end, we define the functions $F_{1}(x / R)=d_{0}+d_{1} \frac{x}{R}, F_{0}(x / R)=\max \left[d_{0}, d_{1} \frac{x}{R}\right]$, and $F_{k}(x / R)=$ $\left[\left(d_{0}\right)^{1 / k}+\left(d_{1} \frac{x}{R}\right)^{1 / k}\right]^{k}$. These same functional forms are defined, and treated, as functions of $x$ in the text to facilitate the statistical comparisons of Table 1. a The additive and piecewise functions $F_{1}(x / R)$ and $F_{0}(x / R)$. b The hyperboloid function $F_{k}(x / R)$ for, from right to left, $k=0.01,0.2,0.4,0.6,0.8$, and 1.0

The threshold $d_{0} / d_{1}$ in the center element of this equation is the transitional value of $x / R$ at which the two arms of this function become equal. The right hand element of Eq. $2 \mathrm{a}$ is the function's simplest algebraic representation. Figure 1a displays the shape of the piecewise musical chairs function.

The threshold and its inverse have clear biological interpretations. Beyond the threshold $x / R=d_{0} / d_{1}$, prey must compete for refuges and hence do not experience maximum refuge-based protection from predators. The inverse of the threshold $d_{1} / d_{0}$ is the smallest number of refuges per individual that still provides this maximum protection.

Fuller interpretation of the piecewise musical chairs function arises from an additional assumption. Assume that 
those deaths that cannot be prevented by eliminating refuge competition occur at the same per capita rate for all values of $x / R$; or equivalently that density-independent deaths occur at the same instantaneous per capita rate $d_{0}$ for all values of $x / R$. In this case, it immediately follows that for large values of $x / R$, all deaths not due to density-independent causes, which take place at instantaneous per capita rate $d_{1}(x / R)-d_{0}=d_{1}\left(x / R-d_{0} / d_{1}\right)$, are density-dependent. Thus, under this additional assumption, the piecewise function can be expressed in a way that shows how density independence and density dependence combine to produce the overall per capita mortality rate,

$f_{0}(x)= \begin{cases}d_{0} & \text { for } \frac{x}{R} \leq \frac{d_{0}}{d_{1}} \\ d_{0}+d_{1}\left[\frac{x}{R}-\frac{d_{0}}{d_{1}}\right] & \text { for } \frac{x}{R}>\frac{d_{0}}{d_{1}}\end{cases}$

This expression reveals that density-dependent deaths occur at a rate proportional to the degree to which the prey to refuge ratio exceeds the threshold $d_{0} / d_{1}$. The biological interpretation is that this difference best represents the intensity of refuge competition that prey experience beyond the threshold ratio of prey to refuges. Observe that the second arm of Eq. $2 b$ has basically the same form as the additive musical chairs function Eq. 1 but with this different measure of prey density. Hence, the function as a whole resembles the additive musical chairs function Eq. 1 but with the purely density-independent phase prepended for $x / R \leq d_{0} / d_{1}$. Although this interpretation helps clarify the ecological basis of the piecewise function, the assumption on which it rests may be questionable and would be difficult to verify empirically (though it underlies the additive musical chairs function Eq. 1, too). For this reason, we shall make no further reference to this assumption or this interpretation throughout the remainder of this paper.

Our third musical chairs function attempts to correct a possible deficiency of the piecewise function, namely that the transition between the density-independent and densitydependent phases is potentially unrealistically abrupt, giving it a stark, bilinear form. We define the hyperboloid musical chairs instantaneous per capita mortality function as

$f_{k}(x)=\left[\left(d_{0}\right)^{1 / k}+\left(d_{1} \frac{x}{R}\right)^{1 / k}\right]^{k}$.

The new parameter satisfies $k \in(0,1)$. In this function, the relative importance of density-independent and densitydependent forces changes gradually rather than abruptly as $x / R$ moves between very small and very large values (Fig. 1b). This is not the only function with this property, but we prefer it because it converges to the piecewise function $f_{0}(x)$ as $k \rightarrow 0$ and to the additive function $f_{1}(x)$ as $k \rightarrow 1$, which means that it accommodates cases intermediate between these two extremes.

\section{A field application}

To evaluate the potential applicability of the musical chairs functions to natural populations, we fitted them, and several plausible alternatives, statistically to experimental survival data for the bridled goby Coryphopterus glaucofraenum, a Caribbean coral reef fish. Bridled gobies maintain home ranges up to a few square meters in area on substrate consisting of sand, coral, and rubble. They feed on sand-dwelling meiofauna and retreat temporarily into crevices at the reef-sand interface whenever threatened or attacked by their predators, which are larger diurnal piscivorous fishes of several species. These generalist predators consume most smaller fish species with which they co-occur, and their abundance is therefore not tightly linked to bridled goby abundance. Each goby typically uses more than one refuge, and some refuges may provide protection for more than one goby at a time. Bridled gobies are known to experience density-dependent predation (Forrester 1995; Forrester and Steele 2000; Steele and Forrester 2005) mediated by competition for refuges (Forrester and Steele 2004; Forrester and Finley 2006).

Forrester and Steele (2004) performed experiments that identified refuge competition as the mechanism of densitydependent mortality in bridled gobies, though the mortality function their analysis employed did not incorporate this mechanism. We focus only on their first experiment, because only it employed study plots of fixed size-a consideration vital to our long-term objective of extrapolating our findings to larger spatial scales. In this experiment, the authors constructed 18 replicate plots of $16 \mathrm{~m}^{2}$ area on a coral reef in the British Virgin Islands within which they manipulated the amount of coral and rock to create a range of refuge densities. In each plot, divers counted the number of structural refuges, or crevices, in which a bridled goby could seek shelter from larger predatory fishes. Divers initially stocked the individual plots with different numbers of marked gobies of very similar body size and then censused the survivors a little over a month later. The gobies grew little over the duration of the experiment. Careful scrutiny of neighboring areas revealed no appreciable movement away from the study plots, and extensive observations over many years have shown only negligible goby movement between reefs. These gobies experience significant mortality from no other source, and so these observations establish that (conservatively) the vast majority of gobies missing from the final census were in fact captured by predators during the experiment. 
We statistically fitted our musical chairs functions and also several conventional instantaneous per capita mortality functions to these experimental data. The candidate functions appear in Table 1. Functions $1-4$ do not involve refuges. The per capita mortality rate in functions 1 and 2 is independent of and directly proportional to prey density, respectively. Function 3, mentioned earlier, is the sum of functions 1 and 2 and is commonly known as a Beverton-Holt mortality function (Quinn and Deriso 1999; Osenberg et al. 2002). Function 4 is similar to the piecewise musical chairs function (Eq. 2a, 2b), but does not account for refuge availability.

In the conventional refuge function 5 (Sih 1987), each prey individual either has full access to an unshared refuge or no access to any refuge, and prey with and without refuges experience deaths at constant per capita rates $d_{0}$ and $d_{1}$, respectively, where $d_{0}$ is expected to be smaller than $d_{1}$. In this function, the overall mortality rate is determined by the difference between the number of prey and the number of refuges. Per capita mortality in function 6 occurs at a rate directly proportional to the ratio of prey to refuges. Hence this function qualifies as a simple musical chairs function, though it lacks density-independent mortality. Our three musical chairs functions 7-9 discussed above restore the possibility of density-independent mortality by combining the density-dependent function 6 in three different ways with the density-independent function 1.

We could not statistically fit these candidate instantaneous per capita mortality functions directly because it is difficult or impossible to measure instantaneous goby death rates under natural conditions. Instead, we calculated the goby abundance at the end of the experiments expected under each candidate function and then iteratively chose those parameter values that minimized the sum of squared differences between the expected and observed final abundances. The iteration procedure employed the solution of the differential equation that describes goby deaths through time, which was calculated either analytically or numerically for the various candidate functions. Optimization was performed using Global Optimization software (Loehle Enterprises) running on Mathematica (ver 6). To evaluate the relative statistical support for the candidate mortality functions, we employed Akaike's Information Criterion corrected for small sample sizes (AICc) (Burnham and Anderson 2002).

This analysis revealed substantially greater support for the three musical chairs functions than for all functions not involving the ratio of gobies to refuges (Table 1). That is, the three musical chairs functions received lower $\mathrm{AIC}_{\mathrm{c}}$ differences $\Delta_{i}$ and higher Akaike weights $w_{i}$ (Burnham and Anderson 2002) than did all other functions. The best-supported function was the piecewise musical chairs function $f_{0}$ (Eq. 2a, 2b). Examination of the second-ranked function actually confirms and strengthens this finding. The hyperboloid function (Eq. 3) ranked second, but only because of the statistical penalty associated with its additional parameter. The fitted value of this parameter, $k=0.0058$, is very close to zero, and the fitted values of $d_{0}$ and $d_{1}$ are indistinguishable from those of the piecewise function. Thus, this analysis has established that the best-fitting 3-parameter hyperboloid function is indistinguishable from its limiting case, the 2-parameter piecewise function.

Figure $2 \mathrm{a}$ provides a visual impression of why the commonly-used Beverton-Holt mortality function (function 3 in Table 1), which accounts for prey density but not the ratio of prey to refuges, received less statistical support than the musical chairs functions. This figure reveals a

Table 1 Parameter estimates and associated Akaike Information Criterion statistics for nine candidate instantaneous per capita mortality functions fitted to the data from Forrester and Steele's (2004) experiment 1

\begin{tabular}{|c|c|c|c|c|c|c|}
\hline Function no. $i$ & Function & $d_{0}$ & $d_{1}$ & $k$ & $\Delta i$ & $w i$ \\
\hline 1 & $d_{0}$ & 0.0218 & - & - & 25.1 & 0 \\
\hline 2 & $d_{1} x$ & - & 0.0009 & - & 20.2 & 0 \\
\hline 3 & $d_{0}+d_{1} x$ & 0.0086 & 0.0005 & - & 21.5 & 0 \\
\hline 4 & $\max \left[d_{0}, d_{1} x\right]$ & 0.0218 & $2.74 \times 10^{-7}$ & - & 25.1 & 0 \\
\hline 5 & $\begin{cases}d_{1} & \text { for } x \leq R \\
d_{0} R+(x-R) / x & \text { for } x>R\end{cases}$ & 0.0212 & $2.74 \times 10^{-7}$ & - & 25.8 & 0 \\
\hline 6 & $d_{1} \frac{x}{R}$ & - & 0.0617 & - & 4.9 & 0.062 \\
\hline 7 & $f_{1}(x)=d_{0}+d_{1} \frac{x}{R}$ & 0.0054 & 0.0437 & - & 4.7 & 0.068 \\
\hline 8 & $f_{0}(x)=\max \left[d_{0}, d_{1} \frac{x}{R}\right]$ & 0.0134 & 0.0573 & - & 0.0 & 0.734 \\
\hline 9 & $f_{k}(x)=\left[\left(d_{0}\right)^{1 / k}+\left(d_{1} \frac{x}{R}\right)^{1 / k}\right]^{k}$ & 0.0134 & 0.0573 & 0.0058 & 3.4 & 0.136 \\
\hline
\end{tabular}

Here, $x$ and $R$ represent the number of gobies and refuges, respectively, per sqaure meter of habitat. The piecewise musical chairs function 8 received the greatest statistical support from the data in this case study 
systematic bias in the Beverton-Holt function's predictions of goby mortality rates: as $x_{\mathrm{i}} / R$ increases (and the points in the figure become darker), the scatter of the observed $x_{\mathrm{f}} / R$ about the best-fitting line also increases and the data points become more likely to fall below it. That is, the BevertonHolt function tended to underestimate the per capita goby mortality rate where the ratio of prey to refuges was high. Figure $2 b$ displays the relationship between initial and final refuge-normalized goby abundances in the experimental data and in the deterministic curve arising from the fitted piecewise musical chairs function. This relationship is calculated from the solution of the differential equation that incorporates $f_{0}$ (Eq. 2a), and shows little systematic bias in the residuals.

These statistical results support four conclusions not revealed by Forrester and Steele's (2004) analysis: (1) When the ratio of gobies to refuges was small, the instantaneous per capita mortality rate was density-independent and given by $d_{0}=0.0134$ per day $(95 \% \mathrm{CI}$ : $[0.0106,0.0159])$. (2) When the ratio of gobies to refuges was large, density-dependent deaths occurred at a per capita rate directly proportional to the ratio of gobies to refuges, with proportionality constant $d_{1}=0.0573$ refuges per goby per day $(95 \%$ CI: $[0.0505,0.0651])$. (3) In the mortality function judged by the $\mathrm{AIC}_{\mathrm{c}}$ criterion as the best description (among those tested) of the experimental data, the transition between the density-independent and densitydependent regions was abrupt rather than gradual. (4) This transition occurred at the threshold value $d_{0} / d_{1}=0.252$ gobies per refuge (95\% CI: [0.197, 0.307]) or 4.74 refuges per goby (95\% CI: [4.05, 6.07]) (assuming that $d_{0}$ and $d_{1}$ are independently normally distributed; Mood et al. 1974).

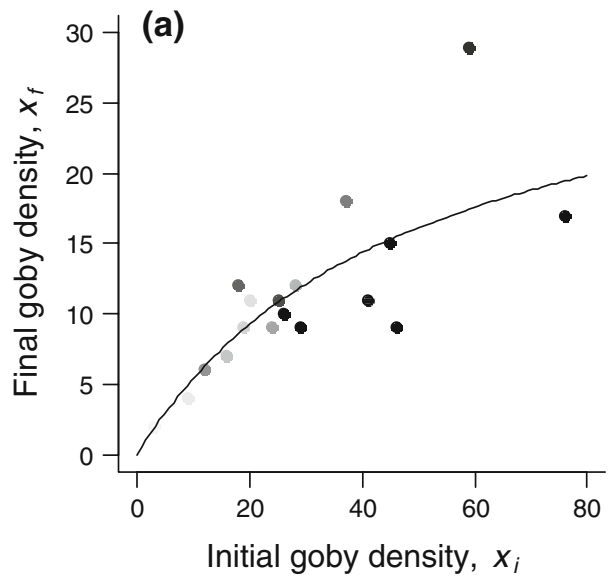

Fig. 2 a Initial $\left(x_{\mathrm{i}}\right)$ and final $\left(x_{\mathrm{f}}\right)$ densities (no. per $\left.4 \mathrm{~m}^{2}\right)$ and $\mathbf{b}$ initial $\left(x_{\mathrm{i}} / R\right)$ and final $\left(x_{\mathrm{f}} / R\right)$ ratios of bridled gobies (Coryphopterus glaucofraenum) from Forrester and Steele's (2004) experiment 1. Fitted curves represent the relationship between these quantities implied by (a) the conventional Beverton-Holt mortality rate function (Table 1, function 3 ) and (b) the solution of the differential equation

\section{Discussion}

Standard models of refuge competition involving a fixed number of refuges assume that the per capita prey mortality rate depends on the arithmetic difference between prey density and refuge density (Rosenzweig and MacArthur 1963; Vance 1978; Sih 1987). This assumption implies a sudden increase in prey vulnerability once prey density exceeds a threshold set by refuge density. For species like the sea urchin Centrostephanus coronatus, in which each individual maintains long-term ownership of a single refuge, this formulation is appropriate. Each urchin hides from predators in its unshared refuge during daylight hours when predators are active, leaves it to forage only at night when predators are absent, and retreats to the same refuge before the predators return at dawn each day. Only individuals lacking refuges experience appreciable predation risk (Nelson and Vance 1979). This assumption may also apply to diurnally active reef fishes that must secure a refuge among coral crevices in which to sleep each night and experience the greatest predation risk during the crepuscular period (e.g., Dascyllus spp.; Holbrook and Schmitt 2002). However, for a wide variety of terrestrial, aquatic, and marine species that forage and engage in other activities away from refuges when their predators are active, and which retreat to shared, unguarded refuges only when predators actually threaten them, the standard formulation does not apply. The mortality functions developed here potentially apply to such prey, in which susceptibility of any prey individual to predation increases progressively with the ratio of prey to refuges.

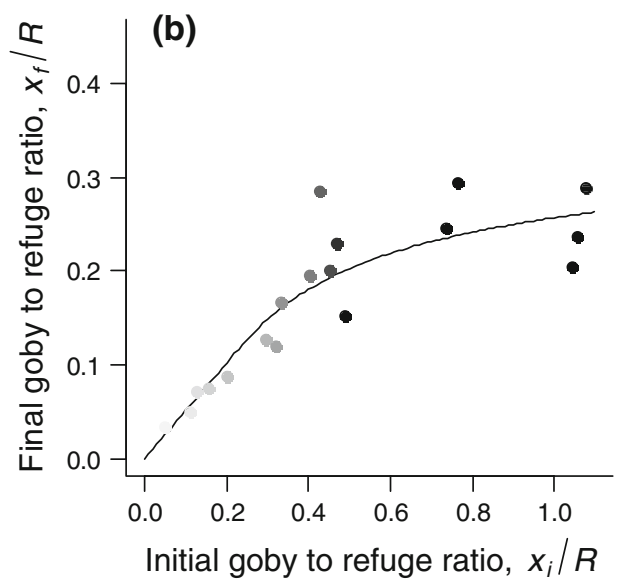

that incorporates the piecewise musical chairs function $f_{0}$ (Eq. 2). Data are color-coded, lighter points represent plots with small values of $x_{i} / R$ and darker points represent plots with large values of $x_{\mathrm{i}} / R$. Note that axes in the two panels differ, representing the use of two different measures of crowding, $x$ vs $x / R$ 
Although we found no suitable published data concerning other species to which we could fit the musical chairs functions statistically, published descriptive information strongly suggests their appropriateness. Like the bridled gobies of Forrester and Steele (2004), many species of marine reef fishes evade larger piscivorous fishes by retreating to shared structural refuges formed by rocks, coral, or macrophytes, and they typically do so only when threatened or attacked (e.g., Ebeling and Laur 1985; Shulman 1985; Hixon and Beets 1993; Caley and St. John 1996; Anderson 2001; Johnson 2006; Caddy 2008). Other marine species, including blue and dungeness crabs, shelter from predators in stands of eelgrass or within other structurally complex substrata (Fernandez et al. 1993; Hovel and Lipcius 2001). Crab survival increases gradually with eelgrass blade density or substratum structural complexity, but also depends on landscape configuration, tidal inundation, and conspecific density (Fernandez et al. 1993; Hovel and Lipcius 2001; Hovel and Fonseca 2005). In freshwater environments, amphibian tadpoles seek cover in pond vegetation to avoid predation by predatory insects, and tadpole survival is correlated with the amount of cover available (Babbitt and Tanner 1998). On land, many species of salamanders retreat to underground burrows to avoid predation by larger terrestrial vertebrates, without necessarily showing strong site fidelity (Regosin et al. 2003; Faccio 2003; Davic and Welsh 2004). In these salamander populations, density can be limited by burrow availability, though the precise relationship between salamander density, burrow abundance, and salamander survival remains less clear. Higher vertebrates such as sparrows seek cover indiscriminately in nearby vegetation when attacked by raptors, but otherwise they spend most of their time foraging and engaged in other activities away from refuge areas (Pulliam and Mills 1977; Lima 1990). As a final example, voles retreat to the nearest and easiest-to-access burrow when threatened or attacked by weasels (Sundell and Ylonen 2004). In all of these examples, experimental or observational evidence suggests that the vulnerability of prey to capture by predators is likely to be an increasing function of the ratio of the number of prey individuals to the abundance of their refuges.

The idea that per capita resource availability strongly influences species' behavior and population dynamics has a long history in ecology (Fretwell and Lucas 1969; Kacelnik et al. 1992; Achord et al. 2003). Our analysis has clearly demonstrated that members of the musical chairs family of instantaneous per capita prey mortality functions, which depend on the ratio of prey to refuges, describe bridled goby deaths better than do functions that depend on either prey density alone or on the arithmetic difference between prey and refuge density. Among the members of this family we examined, the piecewise function provided the best statistical fit to the bridled goby data. Although our analysis did not identify the piecewise function as the best of all possible mathematical descriptions of the data, its excellent statistical fit qualifies this function as a suitable starting point for developing mortality functions that apply on much larger spatial scales.

The piecewise musical chairs function bears some similarity to the hockey stick stock-recruitment function used by fisheries biologists (Barrowman and Myers 2000), and to other models including alternative density-dependent regimes defined by a threshold population density (e.g., Framstad et al. 1997; Post et al. 2002). However, in contrast to the hockey stick function, in the piecewise musical chairs function the shift from a density-independent to a density-dependent process occurs at a threshold set by the ratio of prey to refuges (rather than by population density) and influences the instantaneous per capita mortality rate (rather than recruit density). Likewise, the additive musical chairs function is basically an enrichment of the Beverton-Holt function (Table 1, compare functions 3 and 7), but provides an additional tool for studying fish species that use structural refuges to escape predators.

Musical chairs mortality functions are potentially applicable to other prey species in which each individual can exploit multiple refuges and each refuge can serve multiple individuals. For such species, the ratio of prey to refuges is likely to be a reliable proxy for the intensity of competition and resulting density-dependent dynamics. The minimal field data required to fit these functions statistically and the flexibility of their mathematical form encourage their use to help discover the mechanisms that drive population dynamics.

Acknowledgments This research benefited greatly from discussions with S. Hamilton, K. Holsman, E. Landaw, C. Osenberg, S. Sandin, and W. White. Criticism of earlier drafts by M. Mangel, D. DeAngelis, J. Fryxell, Y. Lucero, J. Shima, C. Osenberg, and two anonymous reviewers improved the presentation. Financial support was provided by an NSF pre-doctoral fellowship, and grants from the AMNH Lerner-Grey Fund, the ASIH Raney Fund, IWFA Ryan Kelley Memorial Scholarship, Sigma Xi Grants-in-Aid of Research, UC Regents, and the UCLA Department of Ecology and Evolutionary Biology to J.F.S., a NOAA-NURP grant to R.R.V. and J.F.S. (CMRC05-PRRV-01-05A), and grants from NSF (OCE 0222087) and NOAA-NURP (CMRC-01-NRME-01-03C, CMRC-03-NRME-01-04A, CMRC-03-NRME-01-05C) to G.E.F., M.A.S., and R.R.V. Views expressed herein are those of the authors and do not necessarily reflect those of CMRC/NOAA.

Open Access This article is distributed under the terms of the Creative Commons Attribution Noncommercial License which permits any noncommercial use, distribution, and reproduction in any medium, provided the original author(s) and source are credited. 


\section{References}

Abrams PA, Walters CJ (1996) Invulnerable prey and the paradox of enrichment. Ecology 77:1125-1133

Achord S, Levin PS, Zabel RW (2003) Density-dependent mortality in Pacific salmon: the ghost of impacts past? Ecol Lett 6:335-342

Ame JM, Halloy J, Rivault C, Detrain C, Deneubourg JL (2006) Collegial decision making based on social amplification leads to optimal group formation. Proc Natl Acad Sci USA 103: $5835-5840$

Anderson TW (2001) Predator responses, prey refuges, and densitydependent mortality of a marine fish. Ecology 82:245-257

Babbitt KJ, Tanner GW (1998) Effects of cover and predator size on survival and development of Rana utricularia tadpoles. Oecologia 114:258-262

Barrowman NJ, Myers RA (2000) Still more spawner-recruitment curves: the hockey stick and its generalizations. Can J Fish Aquat Sci 57:665-676

Berryman AA, Hawkins BA (2006) The refuge as an integrating concept in ecology and evolution. Oikos 115:192-196

Burnham KP, Anderson DR (2002) Model selection and multimodel inference. Springer, New York

Butler MJ, Herrnkind WF (1997) A test of recruitment limitation and the potential for artificial enhancement of spiny lobster (Panulirus argus) populations in Florida. Can J Fish Aquat Sci 54:452-463

Caddy JF (2008) The importance of cover in the life histories of demersal and benthic marine resources: a neglected issue in fisheries assessment and management. Bull Mar Sci 83:7-52

Caley MJ, St. John JS (1996) Refuge availability structures assemblages of tropical reef fishes. J Anim Ecol 65:414-428

Cosner C, DeAngelis DL, Ault JS, Olson DB (1999) Effects of spatial grouping on the functional response of predators. Theor Popul Biol 56:65-75

Davic RD, Welsh HH (2004) On the ecological role of salamanders. Annu Rev Ecol Evol Syst 35:405-434

Ebeling AW, Laur DR (1985) The influence of plant cover on surfperch abundance at an offshore temperate reef. Environ Biol Fishes 12:169-179

Eggleston DB, Lipcius RN (1992) Shelter selection by spiny lobster under variable predation risk, social conditions, and shelter size. Ecology 73:992-1011

Faccio SD (2003) Postbreeding emigration and habitat use by Jefferson and spotted salamanders in Vermont. J Herpetol $37: 479-489$

Fernandez M, Iribarne O, Armstrong D (1993) Habitat selection by young-of-the-year Dungeness crab Cancer magister and predation risk in intertidal habitats. Mar Ecol Prog Ser 92:171-177

Forrester GE (1995) Strong density-dependent survival and recruitment regulate the abundance of a coral reef fish. Oecologia 103:275-282

Forrester GE, Finley RJ (2006) Parasitism and a shortage of refuges jointly mediate the strength of density dependence in a reef fish. Ecology 87:1110-1115

Forrester GE, Steele MA (2000) Variation in the presence and cause of density-dependent mortality in three species of reef fishes. Ecology 81:2416-2427

Forrester GE, Steele MA (2004) Predators, prey refuges, and the spatial scaling of density-dependent prey mortality. Ecology 85:1332-1342

Framstad E, Stenseth NC, Bjoernstad ON, Falck W (1997) Limit cycles in Norwegian lemmings: tensions between phase-dependence and density-dependence. Proc R Soc B Biol Sci 264:31-38

Fretwell SD, Lucas HL (1969) On territorial behavior and other factors influencing habitat distribution in birds. Acta Biotheor 19:16-36
González-Olivares E, Ramos-Jiliberto R (2003) Dynamic consequences of prey refuges in a simple model system: more prey, fewer predators and enhanced stability. Ecol Model 166: 135-146

Hixon MA, Beets JP (1993) Predation, prey refuges, and the structure of coral-reef fish assemblages. Ecol Monogr 63:77-101

Hixon MA, Jones GP (2005) Competition, predation, and densitydependent mortality in demersal marine fishes. Ecology 86: 2847-2859

Holbrook SJ, Schmitt RJ (2002) Competition for shelter space causes density-dependent predation mortality in damselfishes. Ecology 83:2855-2868

Hovel KA, Fonseca MS (2005) Influence of seagrass landscape structure on the juvenile blue crab habitat-survival function. Mar Ecol Prog Ser 300:179-191

Hovel KA, Lipcius RN (2001) Habitat fragmentation in a seagrass landscape: patch size and complexity control blue crab survival. Ecology 82:1814-1829

Jeffries MJ, Lawton JH (1984) Enemy free space and the structure of ecological communities. Biol J Linn Soc 23:269-286

Johnson DW (2006) Predation, habitat complexity, and variation in density-dependent mortality of temperate reef fishes. Ecology 87:1179-1188

Kacelnik A, Krebs JR, Bernstein C (1992) The ideal free distribution and predator-prey populations. Trends Ecol Evol 7:50-55

Koivunen V, Korpimaki E, Hakkarainen H (2003) Refuge sites of voles under owl predation risk: priority of dominant individuals? Behav Ecol 9:261-266

Lima SL (1990) Protective cover and the use of space-different strategies in finches. Oikos 58:151-158

Mood AM, Graybill FA, Boes DC (1974) Introduction to the theory of statistics, 3rd edn. McGraw-Hill, New York

Nelson BV, Vance RR (1979) Diel foraging patterns of the sea urchin Centrostephanus coronatus as a predator avoidance strategy. Mar Biol 51:251-258

Osenberg CW, St Mary CM, Schmitt RJ, Holbrook SJ, Chesson P, Byrne B (2002) Rethinking ecological inference: density dependence in reef fishes. Ecol Lett 5:715-721

Post E, Stenseth NC, Peterson RO, Vucetich JA, Ellis AM (2002) Phase dependence and population cycles in a large-mammal predator-prey system. Ecology 83:2997-3002

Pulliam HR, Mills GS (1977) Use of space by wintering sparrows. Ecology 58:1393-1399

Quinn TP, Deriso RB (1999) Quantitative fish dynamics. Oxford University Press, New York

Rangeley RW, Kramer DL (1998) Density-dependent antipredator tactics and habitat selection in juvenile pollock. Ecology 79:943-952

Regosin JV, Windmiller BS, Reed JM (2003) Influence of abundance of small-mammal burrows and conspecifics on the density and distribution of spotted salamanders (Ambystoma maculatum) in terrestrial habitats. Can J Zool 81:596-605

Riihimaki J, Vehvilaeinen H, Kaitaniemi P, Koricheva J (2006) Host tree architecture mediates the effect of predators on herbivore survival. Ecological Entomol 31:227-235

Rosenzweig ML, MacArthur RH (1963) Graphical representation and stability conditions of predator-prey interactions. Am Nat 97:209-223

Ruxton GD (1995) Short term refuge use and stability of predatorprey models. Theor Popul Biol 47:1-17

Schmitt RJ, Holbrook SJ (2007) The scale and cause of spatial heterogeneity in strength of temporal density dependence. Ecology 88:1241-1249

Shulman MJ (1985) Coral reef fish assemblages: intra-and interspecific competition for shelter sites. Environ Biol Fishes 13:81-92 
Sih A (1987) Prey refuges and predator-prey stability. Theor Popul Biol 31:1-12

Sih A, Petranka JW, Kats LB (1988) The dynamics of prey refuge use - a model and tests with sunfish and salamander larvae. Am Nat 132:463-483

Steele MA, Forrester GE (2005) Small-scale field experiments accurately scale up to predict density dependence in reef fish populations at large scales. Proc Nat Acad Sci USA 102: 13513-13516

Sundell J, Ylonen H (2004) Behaviour and choice of refuge by voles under predation risk. Behav Ecol Sociobiol 56:263-269
Vance RR (1978) Predation and resource partitioning in one predatortwo prey model communities. Am Nat 112:797-813

Wahle RA, Steneck RS (1991) Recruitment habitats and nursery grounds of the American lobster Homarus americanus: a demographic bottleneck? Mar Ecol Prog Ser 69:231-243

White JW (2008) Spatially coupled larval supply of marine predators and their prey alters the predictions of metapopulation models. Am Nat 171:E179-E194 